\title{
Comparison the effectiveness of manual therapy, electrotherapy and core stability exercise vs electrotherapy, traction and traditional exercise for acute low back pain
}

\begin{abstract}
Background: Worldwide most adult population would suffer acute low back pain with some disabilities at some stage of life almost without specific cause but it is essential to manage pain to prevent transition to chronic pain which presents a significant individual, social and economic burden.

Objective: To compare effectiveness of manual therapy, electrotherapy and core stability exercise vs electrotherapy, traction and traditional exercise for acute low back pain.

Methodology: It was a double blind study in which 52 subjects of 46 year mean age were randomized in control and intervention groups. All the subjects were selected from different occupation through assessment, interview, who was suffering central, unilateral or bilateral low back pain less than three months. Subjects of both groups were agreed to receive the allocated treatment for continuous four weeks and follow up the instructions. To measure the effectiveness of this study numerical point box scale for pain, modified Schober method for flexion, extension range and Quebec Back Pain Disability Scale was used.

Result: From the measurement, the intervention group showed better improvement and performance in all aspects than the control group. The measurements showed the difference of deviation pain reduction box scale 2.99 , flexion 0.28 , extension 0.82 , disability scale 14.21 was in control group and pain reduction 5.20 , flexion 1.47 , extension 1.30 ; disability scale 22.83 was in intervention group.
\end{abstract}

Conclusion: Manual therapy, core stability exercises with other treatments can be effective for acute low back pain but further research should be done in this respect.

Keywords: acute low back pain, manual therapy, core stability exercise, electrotherapy
Volume 2 Issue 2 - 2015

\author{
Dolilur Rahman,' Israt Jahan, ${ }^{2}$ Shahid Uddin, ${ }^{3}$ \\ Zakir Uddin, ${ }^{4}$ Shofiqul Islam, ${ }^{5}$ Monoarul \\ Haque $^{6}$ \\ 'East-West Medical College, Bangladesh \\ ${ }^{2}$ Department of Physiotherapy, East-West Medical College \\ Hospital, Bangladesh \\ ${ }^{3}$ Consultant of Medicine \& Cardiology, Bangladesh \\ ${ }^{4}$ Department of Medicine \& Cardiology, Gono Bishwabidyalay, \\ Bangladesh \\ ${ }^{5}$ BIHS Diabetic Association, Bangladesh \\ ${ }^{6}$ Department of Community Nutrition, Bangladesh University of \\ Health Sciences, Bangladesh
}

\begin{abstract}
Correspondence: Monoarul Haque, Department of Community Nutrition, Faculty of Public Health, Bangladesh University of Health Sciences (BUHS), I 25/I, Darus Salam, Mirpur, Dhaka-1216, Bangladesh, Tel 88 01915839550, Emailmonoarmunna@yahoo.com
\end{abstract}

Received: January 18, 2015 | Published: March 10, 2015

\section{Background}

Low back pain (LBP) is a leading cause of disability; it occurs in similar proportion in all cultures, interferes with quality of life $\&$ work performance \& is most reason for medical consultation. ${ }^{1-4}$ Low back pain is common worldwide, affecting approximately $70 \%$ of the adult population at some stage of life. ${ }^{5-9}$ The cause of pain is non-specific in about $95 \%$ of people presenting with acute low back pain, and serious conditions are rare. ${ }^{10,11}$ However, in the absence of serious cause, it is not necessary to know the specific diagnosis in order to manage the pain effectively. The term acute is used to describe pain that has been present for less than three months; ${ }^{12}$ it does not refer to the severity or quality of pain. Chronic low back pain is a well-documented disabling condition, costly to both individuals and society. ${ }^{13}$ LBP is a disabling disorder that greatly affects society; it is a burden for the individual patient and additional cost for the society because loss of work and medical expenses. Therefore, adequate treatment of LBP is an important issue for patients, treating clinicians and health care policymakers.

Movement is a continuous process from birth to increase aging which plays an important role in people's lives. We start to move in the womb before we are born, and advance from the typical movements of the infant to the energetic ones of the young child and go on via puberty into adulthood, after which movement slows down and often requires assistance at older age. Movement is a major component of the way people interact with the environment and with each other and is part of virtually all-human activity. With more moving parts than most machines, it is not surprising that your body cries out occasionally or refuses to do what we want to do. Low back pain is one of the most common problem where lot of activities and movements going to be restricted. Choosing an effective intervention strategy for achieving the best rehabilitation outcome represents a significant clinical challenge in acute low back pain. Within Physiotherapy management manual therapy with core stability exercise can be a safe and effective way of treatment to repair damage by speeding up healing process, reduce pain \& stiffness and increase overall mobility with functional activities.

\section{Methodology}

This study was experimental and conducted in Physiotherapy department of Gonoshasthatya \& East- West Medical College Hospital from May 2007 to Feb 2008. The materials such as pen, pencil, and paper, assessment sheet, measuring tape, table, towel, Ultrasound, oil, TENS, exercise \& posture education guidelines, questionnaire 
were used in this study. About 52 subjects of male and female from different occupations were selected through assessment on the basis of suffering low back pain for maximum three months with aging 30 to 55 year. Selection of subjects was on from central, unilateral \& bilateral back pain with agreement of informed consent to continue and follow up the treatment procedure for 4 weeks and requested to inform any recurrent in future. They had also the opportunity to drop out from the study. All the subjects were randomized, 27 subjects in control group and 25 subjects in intervention group. The intervention group was allocated for Manual therapy, Electrotherapy \& Core stability Exercise and control group was allocated for Electrotherapy $\&$ Traction with traditional Exercise and patient education for both groups. The assessor and patients were not informed about the effect of the study for more reliability.

\section{Intervention}

Within first two weeks manual therapy, electrotherapy for intervention group and electrotherapy with traction for control group and patient educations for both groups were provided to relief pain. Electrotherapy such as ultrasound therapy, TENS, intermittent pelvic traction and back \& trunk strengthening exercises were provided for the control group and manual therapy such as mobilization, manipulation, deep tissue massage, myofascial release with trigger point therapy, muscle energy techniques, electrotherapy \& core stability exercises were provided for the intervention group. Posture education and stay active were encouraged for both groups. All exercises were trained and prescribed after control of pain. For back \& trunk strengthening unilateral, bilateral legs and head raising, lowering, and holding in supine and prone position. For core stability exercise Australian spinal stabilization approach was used with traditional exercises. According to Australian spinal stabilization approach initially transverse abdominis activation was performed in supine lying with finger tips-positioned just inside the front corners of the pelvis followed by combined transverse abdominis and multifidus activation was performed in prone position. Then therapeutic dynamic middle layer exercises were performed with above two muscles activation and continue these exercises for 3 months.

\section{Measurement}

a. To assess the severity of pain the numerical rating scale point box was used where numbers between 0 and 10 appear and patients were asked to mark the box that reflects the pain intensity where zero (0) means no pain and ten (10) means the worst pain ever.

b. To measure disability scale the Quebec Back Pain Disability Scale was used where 12 questionnaires were selected (60 maximum, 0 minimum) and the scale of each activity was counted 0 to 5 , where $0=$ Not Difficult at all, $1=$ Minimally Difficult, $2=$ Somewhat Difficult, 3=Fairly Difficult, 4= Very Difficult, 5= unable to do. The 12 questionnaires were used on get out of bed, sleep through night, turn over in bed, sit in a chair for several hours, stand up for 20-30 minutes, climb one flight of stairs, walk a few blocks (300-400m), reach up to high shelves, throw a ball, make your bed, bend over to clean the bathtub, move a chair.

c. To measure the lumbar flexion and extension range of motion modified Schober method was used. For measurement of flexion and extension range of motion patient's foot, knee and head position were standardized and the tape measure was placed flat against the patient's skin to measure $15 \mathrm{~cm}$ cephalad to the line joining the PSIS. The distance between the PSIS and cephalad landmark is measured. In neutral this distance was $15 \mathrm{~cm}$, in flexion the distance increases and in extension the distance decreases. The difference between the original $15 \mathrm{~cm}$ and the new shorter distance to the skin mark was recorded.

\section{Results}

For the result of this study, pre and post assessment was done in both groups on pain point box, flexion \& extension range and disability scale were showed into column, bar chart and cylinder graph. From the result of both groups the Visual Analogue Scale (VAS) \& Disability scale were decreased and Flexion \& extension range were increased in different ranges. From the VAS assessment the average reduction of pain intensity was 4.23 scales (52\%) in control group and 7.35 scale $(87 \%)$ in intervention group (Figure 1). The average flexion range was increased. $4 \mathrm{~cm}(31 \%)$ in control group and $2.08 \mathrm{~cm}(79 \%)$ in intervention group (Figure 2). From the Figure 3, it is indicated that the extension range was decreased $1.17 \mathrm{~cm}(56 \%)$ in control group and $1.84 \mathrm{~cm}(74 \%)$ in intervention group. The reduction of disability scale was 20.04 score $(51 \%)$ in control group and 32.28 score $(85 \%)$ in intervention group (Figure 4).

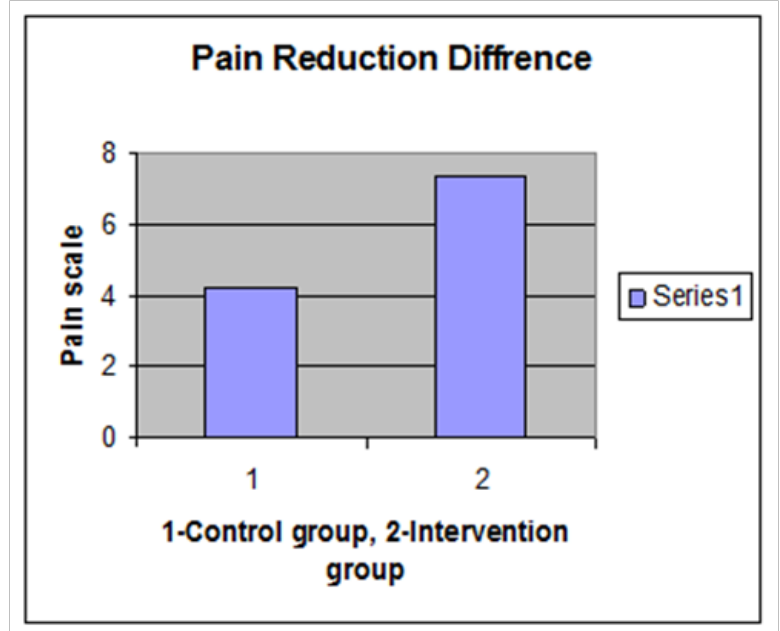

Figure I Reduction of pain intensity among control and intervention group.

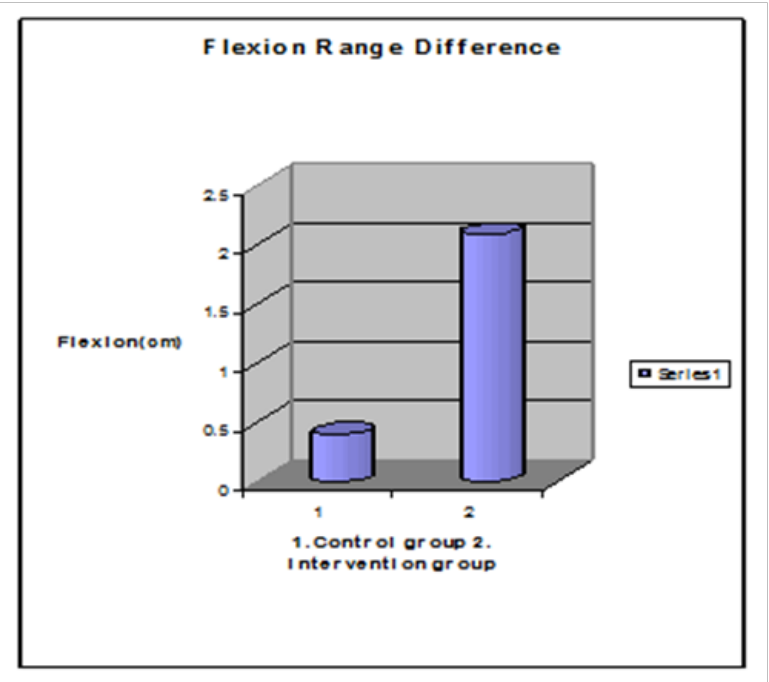

Figure 2 Flexion range difference among control and intervention group. 


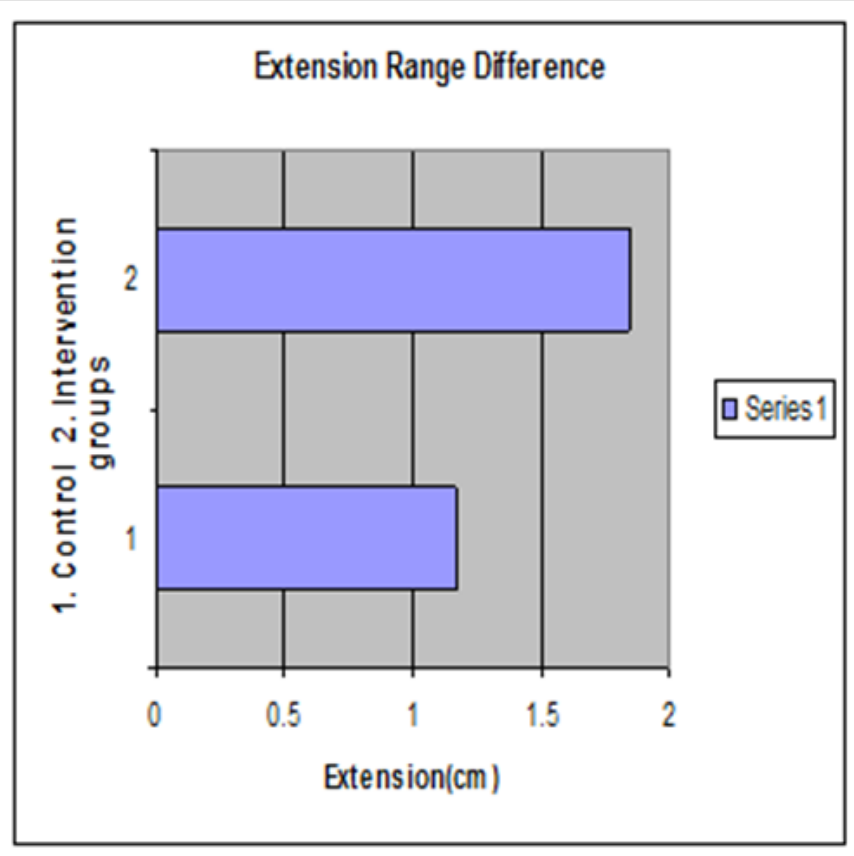

Figure 3 Extension range difference among control and intervention group.

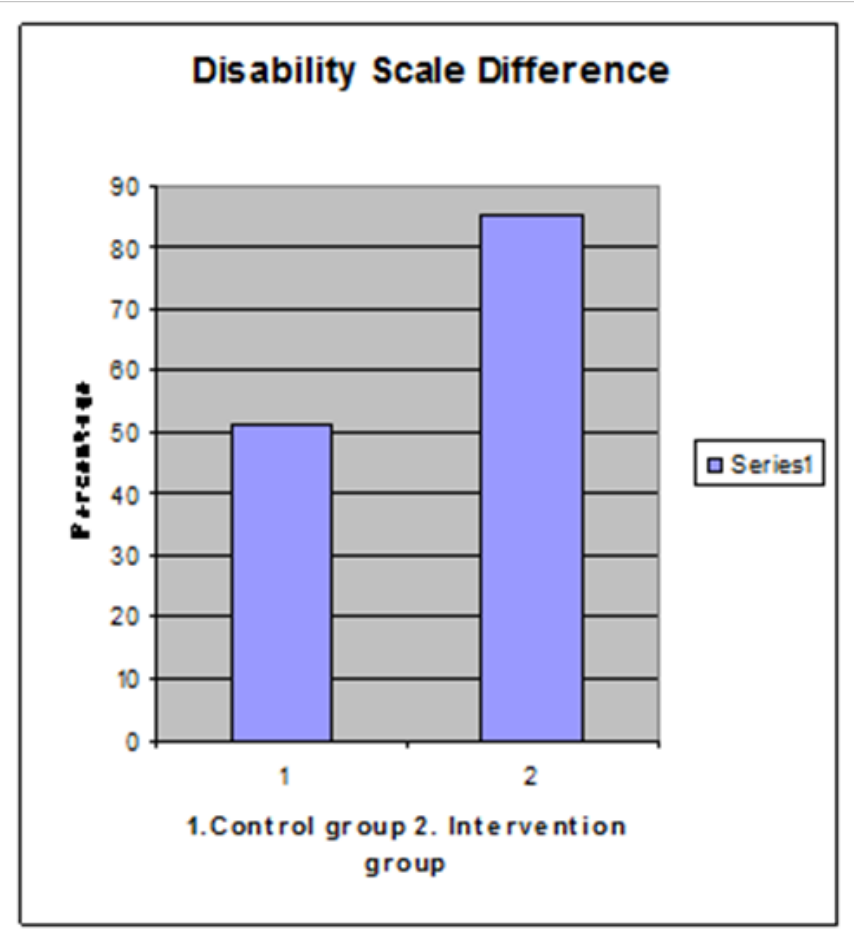

Figure 4 Disability scale difference among control and intervention group.

\section{Discussion}

Traditionally, strengthening exercises for weak abdominal and back muscles were assumed someway is therapeutic. About $90 \%$ of people with acute low back pain will have their pain resolve within 8 weeks regardless traditional treatment or not but worse still, $70 \%$ of those who fully recover in 8 weeks can expect to experience progressive episode of low back pain in future. Manual therapy was found to be effective in reducing pain in the non-pharmacological management of acute LBP. ${ }^{14,15}$ They also stated that participants receiving manual therapy combined with exercise, electrotherapy and posture education reported experiencing less pain, depression, anxiety \& their sleep had improved.

Regarding treatment of low back pain, success rates were unheard of in the scientific literature. Most importantly, the patients who were treated with the Australian approach were 12 times less likely to experience repeat low back pain during the first year following their treatment. ${ }^{16,17}$ Exercise therapy, massage, mobilization are widely used as intervention in LBP, they appear to be effective at decreasing pain \& improving function in adults with acute LBP. ${ }^{18-21}$ Circuit training is good for LBP, which includes aerobic \& strengthening regimes with emphasize postural control, spinal stability, back extensor \& deep abdominal musculature. ${ }^{22,23}$ The use of extensor exercises, flexibility \& strengthening activities \& pelvic neutral exercises will accomplish to relieve central low back pain. ${ }^{24-26}$ Exercise \& education is a common physiotherapy approach in the prevention of LBP, a program of exercises \& ergonomic education seems efficient in reducing recurrent episodes of LBP at 3 year-follow-up. ${ }^{27}$

All the subjects followed and completed the treatment program except two subjects dropped out from the control group which did not have effect in the study. Women were more in numbers who were most housewife and their pain intensity $\&$ disability scale were more than men. In the aspects of improvement it was more in men than women reason may be biopsychosocial issues but there was more improvement in manual therapy group though psychosocial aspects were not properly investigated and managed. The subjects of intervention group did not come further but some came further with recurrent problem of control groups.

\section{Conclusion}

LBP is one of the most common and costly musculoskeletal problems in society and many back pain 'treatment options' have been promoted over the years as different health care professionals, working with the best information available, tried to devise methods of providing good rehabilitative care for people with bad backs. ${ }^{28,29}$ From the result of this study and literature review that manual therapy and core stability exercises with other interventions which have been described above can be the choice able treatment interventions for management of acute low back pain. Overall further research in more population with succinct scientific procedure should be done for more reliability and validity of this study.

\section{References}

1. Ehrlich GE. Low back pain. Bull World Health Organ. 2003;81(9):671676.

2. Ernst E. Massage treatment for back pain. BMJ. 2003;326(7389):562563.

3. Fritz S. Sports and exercise massage, Comprehensive care for athletics, fitness and rehabilitation. Mosby, Elsevier, New York, USA, 2005;pp. 472 .

4. Frost H, Lamb SE, Doll HA, et al. Randomised controlled trial of physiotherapy compared with advice for low back pain. $B M J$. 2004;329(7468):708. 
5. Hollingworth W, Todd CJ, King $\mathrm{H}$, et al. Primary care referrels for lumbar spine radiography: diagnostic field and clinical guidelines. $\mathrm{Br} J$ Gen Pract. 2002;52(479):475-480.

6. Australian Acute Musculoskeletal Pain Guidelines Group (AAMPGG) Evidence-Based Management of Acute Musculoskeletal Pain. National Health and Medical Research Council, Australia, 2003;pp. 259.

7. Basmajian VJ, Nyberg R. Rational Manual therapies. Williams and Wilkins, USA, 1993;pp. 464

8. Bekkering GE, Hendriks HM, Koes BW, et al. Dutch Physiotherapy Guidelines for low back pain. Physiotherapy. 2003;89(2):82-96.

9. Deyo RA, Rainville J, Kent DL. what can the history and physical examination tell us about low back pain? JAMA. 1992;268(6):760-765.

10. Deyo RA, Tsui-Wu YJ. Descriptive epidemiology of low back pain and its related medical care in the United States. Spine (Phila Pa 1976). 1987;12(3):264-268.

11. Suarez-Almazor ME, Belseck E, Russel AS, et al. Use of lumbar radiographs for the early diagnosis of low back pain: proposed guidelines would increase utilization. JAMA. 1997;277(22):1782-1786.

12. Merskey H. Pain terms: a list with definitions and notes on usage recommended by the IASP Subcommittee on Taxonomy. Pain. $1979 ; 6(3): 249$

13. Waddell G. Biopsychosocial analysis of low back pain. Baillieres Clin Rheumatol. 1992;6(3):523-557.

14. Hernandez RM, Field T, Kresnegor J, et al. lower back pain is reduced and range of motion increased after massage therapy. Int $J$ Neurosci. 2001;106(3-4):131-145.

15. Preyde M. Effectiveness of massage therapy for subacute low back pain: A randomized controlled trials. CMAJ. 2000;162(13):1815-1820.

16. Hides JA, Richardson CA, Jull GA.MRI and Ultrasonography of the lumbar multifidus and transverse abdominis. Spine. 2004;20:554-558.

17. Hodges PW, Richardson CA. Delayed postural contraction of transverse abdominis in low back pain associated with movement of the lower limbs. J Spinal Disord. 1998;11(1):46-56.
18. Hayden JA, Van Tulder MW, Malmivaara, A, et al. Exercise therapy for the treatment of non-specific low back pain. Cochrane Database Syst Rev. 2005;(3):CD000335.

19. Hsieh CJ, Adams AH, Tobis J, et al. Effectiveness of four conservative treatments for subacute low back pain. Spine. 2002;27(11):1142-1148.

20. Hurwitz LE, Morgenstem H, Chiao. The effect of physical activity and back exercise on low back pain and psychological distress. Am J Public Health. 2005;95(10):1817-1824.

21. Zuluaga M, Briggs C, Carlisle J, et al. Sports Physiotherapy: Applied science and Practice. (1st edn), Churchill Livingstone, New York, USA, 1995;pp. 529

22. Merskey H, Bogduk N. Description of chronic pain syndromes and definitions of pain terms Classification of chronic pain. (2nd edn), IASP Press, Washington, 1994;USA.

23. Porter S. Tidys Physiotherapy. (13th edn), Churchill Livingstone, New York, USA, 2003;p. 39-41.

24. Houglum AP. To relieve central pain. Therapeutic exercises for musculoskeletal injuries. (2nd edn), Human Kinetics, UK, 2005;pp. 527.

25. Julie DA. Good exercises for bad backs. Emmaus. 2006;58(3):44.

26. Kofotolis N, Sambanis M. The influence of exercise on musculoskeletal disorders of the lumbar spine. J Sports Med Phys Fitness. 2005;45(1):84 92.

27. Soukup MG, Lonn J, Glomsrod B, et al. Exercise and education as secondary prevention for recurrent low back pain. Physiother Res Int 20016(1):27-39.

28. Furlan AD, Brosseau L, Imamura M, et al. Massage for low back pain: a systematic review within the framework of the cochrane collaboration back review group. Spine (Phila Pa 1976). 2002;27(17):1896-1899.

29. Hay EM, Mulli SR, Lewis M, et al. Comparison of physical treatments versus a brief pain management programme for back pain in primary care. Lancet. 2005;365(9476):2024-2030. 